\title{
SARCOMATOID DIFFERENTIATION IN RENAL CELL CARCINOMA: PROGNOSTIC IMPLICATIONS
}

\author{
MARCOS F. DALL'OGLIO, MARCO LIEBERKNECHT, VALTER GOUVEIA, ALEXANDRE C. \\ SANT'ANNA, KATIA R. LEITE, MIGUEL SROUGI \\ Division of Urology, Paulista School of Medicine, Federal University of Sao Paulo, UNIFESP, \\ Sao Paulo, SP, Brazil
}

\begin{abstract}
Introduction: Renal cell carcinoma with sarcomatoid differentiation is a tumor with aggressive behavior that is poorly responsive to immunotherapy. The objective of this study is to report our experience in the treatment of 15 patients with this tumor.

Materials and Methods: We retrospectively analyzed 15 consecutive cases of renal cell carcinoma with sarcomatoid differentiation diagnosed between 1991 and 2003. The clinical presentation and the pathological stage were assessed, as were the tumor's pathological features, use of adjuvant immunotherapy and survival. The study's primary end-point was to assess survival of these individuals.

Results: The sample included 8 women and 7 men with mean age of 63 years (44 - 80); follow-up ranged from 1 to 100 months (mean 34). Upon presentation, $87 \%$ were symptomatic and 4 individuals had metastatic disease. Mean tumor size was $9.5 \mathrm{~cm}(4-24)$ with the following pathological stages: 7\% pT1, 7\% pT2, 33\% pT3, and 53\% pT4. The pathological features showed high-grade tumors with tumoral necrosis in $87 \%$ of the lesions and $80 \%$ of intratumoral microvascular invasion. Disease-free and cancer-specific survival rates were 40 and $46 \%$ respectively, with 2 cases responding to adjuvant immunotherapy.

Conclusions: Patients with sarcomatoid tumors of the kidney have a low life expectancy, and sometimes surgical resection associated with immunotherapy can lead to a long-lasting therapeutic response.
\end{abstract}

Key words: kidney neoplasms; carcinoma; renal cell; neoplasms metastasis

Int Braz J Urol. 2005; 31: 10-16

\section{INTRODUCTION}

Every year, renal cell carcinoma (RCC) is responsible for approximately $2 \%$ of new cases of cancer in the United States and for the highest proportion of cancer-associated deaths in relation to all other malignant urological diseases (1).

Initially called carcinosarcoma (2), mixed renal tumor (3), and subsequently renal sarcomatoid tumor according to Farrow et al. (4), the sarcomatoid differentiation is not a distinct histological entity and confers higher aggressiveness on any of the different subtypes of RCC, with a frequency ranging from 1 to $8 \%$ in the series (4-6). Studies indicate that the presence of a sarcomatoid component makes the disease locally aggressive, which typically presents an advanced grade that is associated with fast progression and fatal outcome in a vast proportion of cases, with median survival lower than 1 year in many series (511). This is important for predicting the outcome for patients undergoing nephrectomy due to RCC, since 
adjuvant therapy in a certain group of patients with higher risk of progressive disease can be a reasonable alternative.

We report our experience with sarcomatoid RCC after assessing its presentation form, the role of the pathology, the tumor's pathological features, the role of adjuvant immunotherapy and the patient survival rate.

\section{MATERIALS AND METHODS}

We retrospectively assessed 231 patients diagnosed with RCC who underwent surgical treatment at our institution from March 1991 to June 2003. The study included 15 patients aged from 44 to 80 years old (mean 63 years) whose pathological examination of the surgical specimen revealed a sarcomatoid component.

For pathological analysis, the specimen is fixed in formalin, embedded in paraffin, sectioned and fixed as usual by hematoxylin-eosin (HE). In addition to sarcomatoid differentiation characterized by elongation of the tumor cells (Figure-1), we analyzed the nuclear grade, pleomorphism, mitotic index and tumoral necrosis. The immunohistochemical analysis was performed in 8 patients with exclusive sarcomatoid differentiation, confirming the presence of an epithelial component.

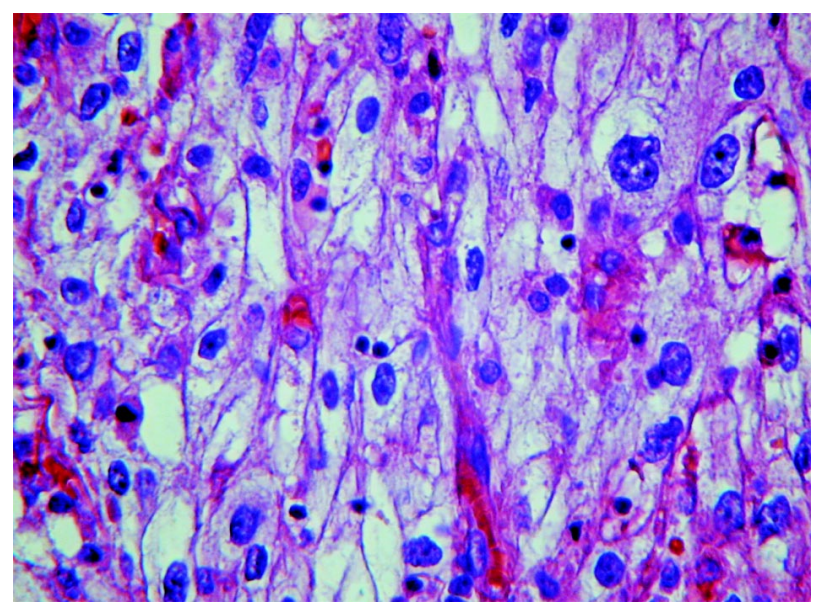

Figure 1 - Photomicrography of sarcomatoid differentiation in clear renal cell carcinoma.
Age, gender and presentation symptoms were assessed, as well as the stage of the disease, the pathological features, the use of adjuvant immunotherapy, the time to recurrence of the disease and the survival of this group of individuals. Postoperative follow-up was bi-annual through hematological and imaging exams with ultrasound interpolated with tomography and chest radiography.

The statistical analysis through survival curves was performed by the Kaplan-Meier method, with the log Rank test being used for comparison.

\section{RESULTS}

Of the 15 patients under study, the mean age was 63 years (44-80), comprising 8 women and 7 men. Upon presentation, $87 \%$ were symptomatic, with pain, weight loss and hematuria being the most frequent complaints. Additionally, in 4 patients the initial presentation was metastatic lesion. Table-1 lists the demographic data of patients under study.

Eight patients had exclusive sarcomatoid differentiation, and 7 patients presented association with clear cell carcinoma (Figure-1).

All patients underwent radical nephrectomy. One woman who presented recurrence in retroperitoneum on 3 occasions underwent resection of the lesion at all times, and has been followed for 6 months now.

Systemic adjuvant treatment was instituted in 2 patients (13.3\%). Patient \#8, whose initial presentation was pulmonary metastatic disease, received adjuvant immunotherapy with interferon and interleukin with full response and disappearance of the pulmonary nodule, remaining free of the disease in 72 months of follow-up. Patient \#11 received adjuvant dendritic cell vaccine and is presenting a good performance status after 56 months of follow-up despite having undergone 3 resections of retroperitoneal masses with pathological diagnosis of sarcomatoid RCC and being submitted to new vaccine applications.

Cancer-specific and disease-free survival curves are represented in Figures-2 and 3, respectively. Mean time to recurrence of the disease was 30 months. Among the total of 8 deaths, 7 were due to progression of the disease within a mean period of 


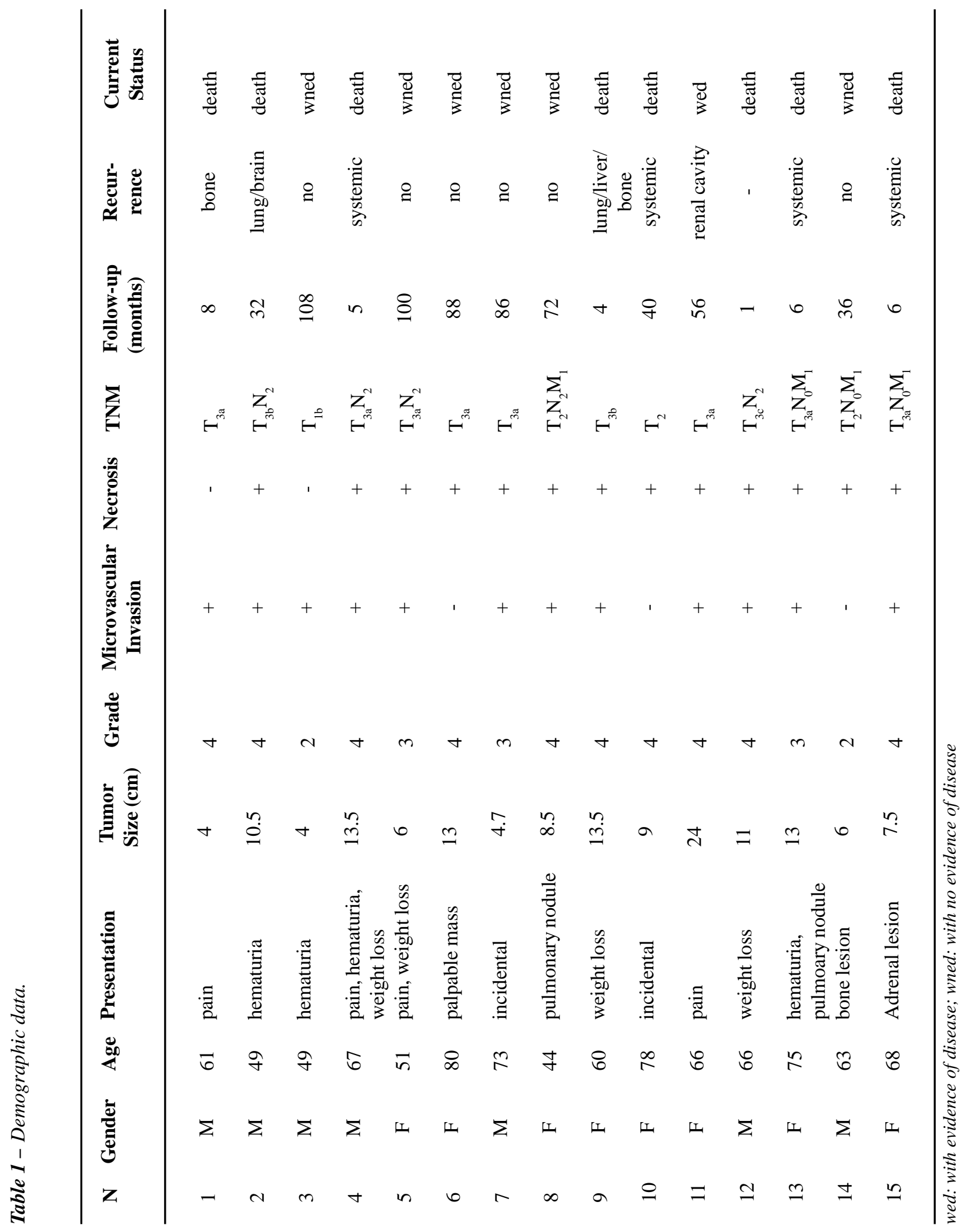




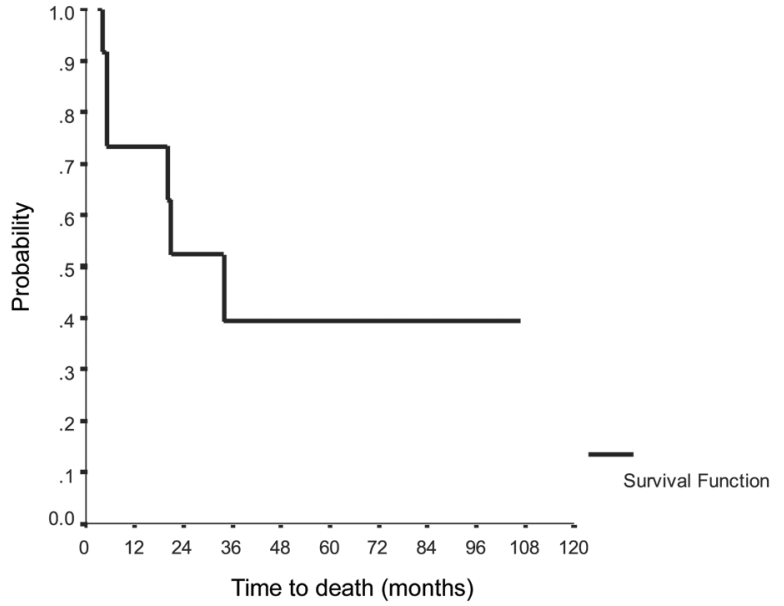

Figure 2 - Cancer specific survival.

17.2 months (4 - 40). A 66-year man (\#12) with a stage $\mathrm{T} 3 \mathrm{cN} 2 \mathrm{M} 0$ tumor who underwent radical nephrectomy by thoracophrenolaparotomy, died as a consequence of pulmonary embolism on the 30th postoperative day.

We observed that $80 \%$ of the surgical specimens had microvascular invasion, $87 \%$ were tumors with high Fuhrman's nuclear grade. Two individuals (14\%) had localized disease (stage I and II), 33\% stage III, and 53\% stage IV.

\section{COMMENTS}

Our work showed that RCC with sarcomatoid differentiation presents an advanced stage and is symptomatic in $87 \%$ of cases, with a mean tumor size of $9.5 \mathrm{~cm}$, with high Fuhrman's nuclear grade, and life expectancy of $40 \%$ within 3 years.

There is controversy as to whether the amount of sarcomatoid tumor is relevant when analyzing the disease's potential for recurrence. In the present series, there is similarity concerning the clinical presentation and the outcome of individuals with pure sarcomatoid tumors compared with tumors associated with clear cell carcinoma. However, when there is more than $50 \%$ of this component, survival is worse $(6,9)$, which is contested by Bertoni et al. (8). Nevertheless, the same author states that only individuals

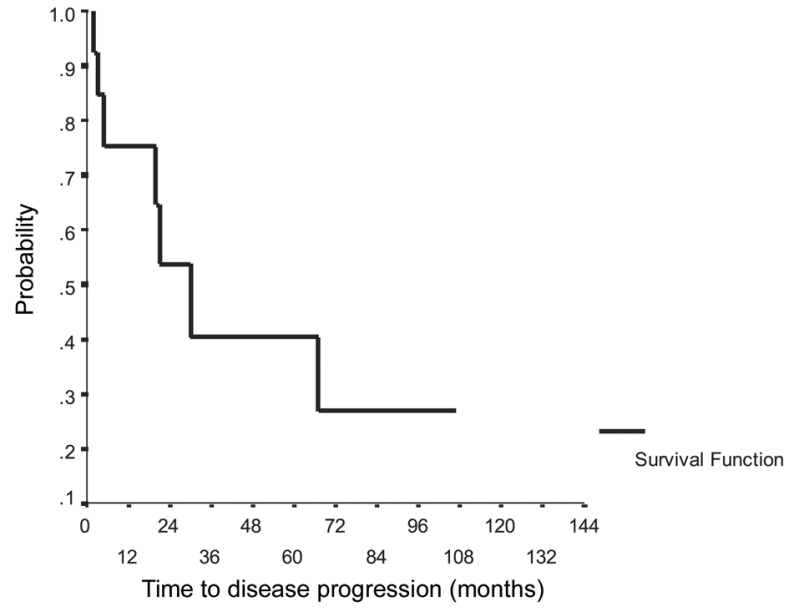

Figure 3 - Disease-free survival.

with low Fuhrman's nuclear grade tumors and less than 5\% of sarcomatoid component have real chances of cure. The frequency of sarcomatoid tumors with high Fuhrman's nuclear grade is $64-100 \%(6,9,12)$, and in our series, $87 \%$ of tumors presented this characteristic.

Some evidence suggests that the sarcomatoid tumor is most often associated with chromophobe RCC (6); however, the histological type does not influence the disease's outcome $(6,9,11)$. In our sample, we did not identify any chromophobe RCC, and the clear cell subtype was identified in half the cases.

Cheville et al. (12) explain the median survival of 8 months in their series as resulting from advanced stage, tumor size and presence of necrosis, with the same significance attributed by Frank et al. (13). Additionally, the presence of necrosis promotes a relative risk of 3.35 (12). For the studied group, in $87 \%$ of cases there was tumoral necrosis.

The fact that these tumors are symptomatic in 86 to $89 \%$ of cases $(11,12)$ and the identification of advanced stage in two-thirds of the cases presenting voluminous tumors explains their aggressiveness potential. Table- 2 displays several studies on sarcomatoid RCC, facilitating a comparative analysis with the present series and confirming the invasive profile of the disease. In our sample, the predominant symptoms were hematuria, pain and emaciation in $75 \%$ of 


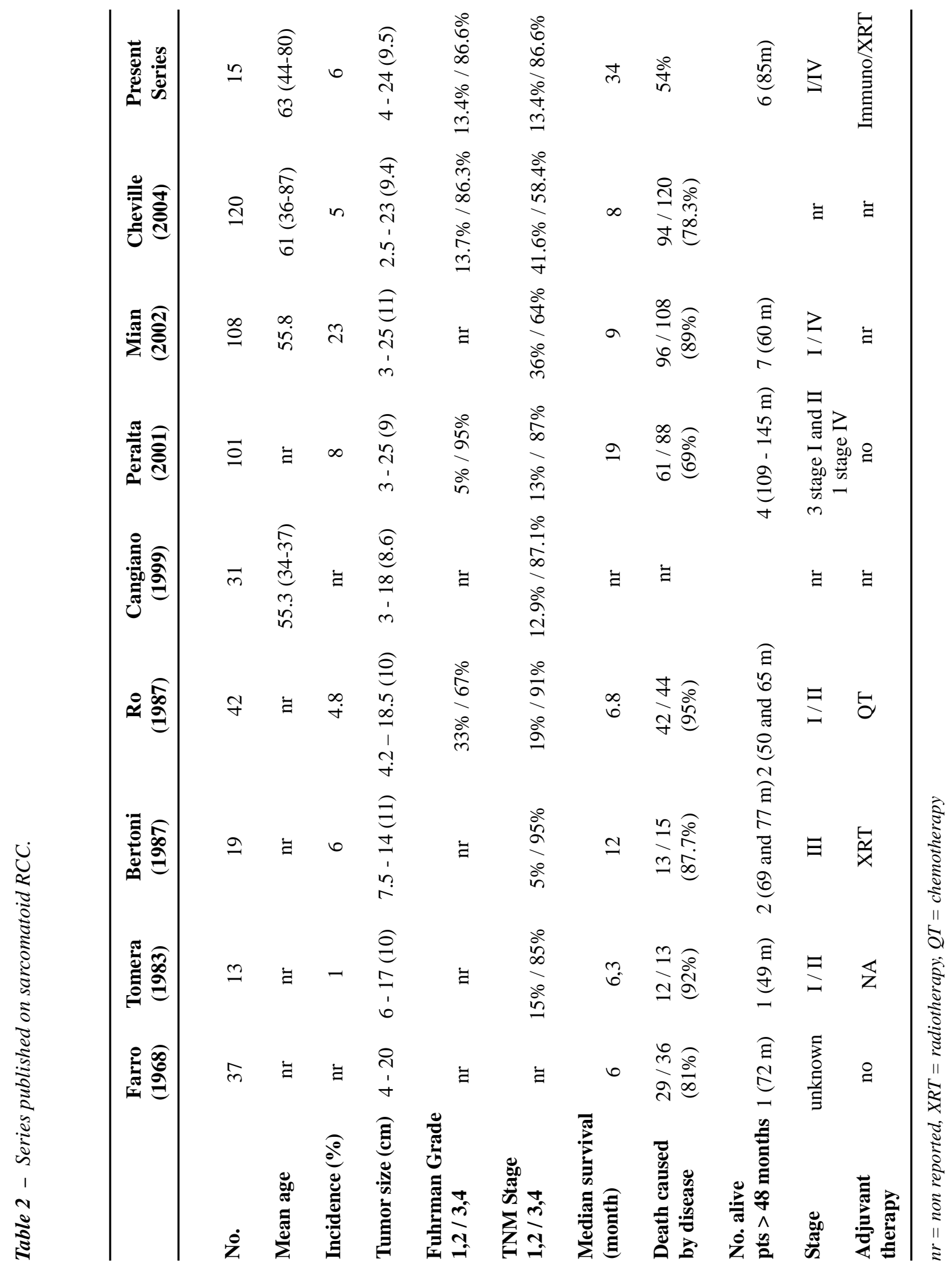


patients, with diagnosis being incidental in only 2 individuals. On the other hand, 4 patients $(26,6 \%)$ had metastatic disease at the time of surgery.

Patients with sarcomatoid RCC have a mean survival of 49.7 months for $\mathrm{pT}_{1}$ stage and 6.8 months for $\mathrm{pT}_{2}-\mathrm{pT}_{4}$ stages $(9,14)$. Other series present global survival lower than 1 year (5-11).

Surgical resection only, does not significantly change the disease's clinical outcome since the majority of these tumors is metastatic or locally advanced at the moment of diagnosis, with a very short survival rates for these patients regardless of the type of treatment $(3-5,7,11,15)$. If left untreated, the sarcomatoid RCC leads to death within a period of 3.8 to 6.8 months $(4,7)$. The potential for aggressiveness of such tumors is highlighted by Cangiano et al. (10), who identified in their series $84 \%$ of metastases at the moment of surgery. Despite controversies concerning the responsiveness of sarcomatoid RCC to chemotherapy and immunotherapy, $(7,10)$ we had satisfactory responses with dendritic cell vaccine in 1 case - a woman who presented a recurrence in the renal cavity and underwent resection of the retroperitoneal mass at 3 occasions with adjuvant vaccine - and who currently has an optimal performance status with 56 months of follow-up. In another patient who received interleukin and interferon adjuvant to nephrectomy, the pulmonary metastatic lesion disappeared and she is alive and disease-free 72 months after surgery. One individual who underwent resection of a trochanteric bone lesion following a pathological fracture and whose specimen revealed metastatic RCC, underwent radical nephrectomy and subsequently femoral radiotherapy, and has been free of disease for 36 months now. The best results for regression of metastases with immunotherapy reach $31 \%$ in 3 years (16); moreover, the rate of full remission with interferon and interleukin2 as monotherapy is 15 to $20 \%$ (17), which are discouraging responses.

As a future perspective, we should consider the possibility of adjuvant therapy for high-risk diseases such as renal sarcomatoid tumors since this treatment is recommended even for localized disease due to the extremely low morbidity of the autologous renal tumor cell vaccine (18).
Individuals diagnosed with RCC with sarcomatoid differentiation present a serious disease with reserved prognosis; however, adjuvant immunotherapy can improve the outcome of some individuals.

Adriana Sañudo performed the statistical analysis.

\section{REFERENCES}

1. Greenlee RT, Murray T, Bolden S, Wingo PA: Cancer statistics, 2000. CA Cancer J Clin. 2000; 50: 7-33.

2. Hou LT, Willis RA: Renal carcino-sarcoma, true and false. J Pathol Bacteriol. 1963; 85: 139-44.

3. Juhasz J, Sebok J, Galambos J, Kiss P: Renal carcinosarcoma (mixed tumours) of the kidney. Int Urol Nephrol. 1980; 12: 103-8.

4. Farrow GM, Harrison EG Jr, Utz DC: Sarcomas and sarcomatoid and mixed malignant tumors of the kidney in adults. 3. Cancer. 1968; 22: 556-63.

5. Tomera KM, Farrow GM, Lieber MM: Sarcomatoid renal carcinoma. J Urol. 1983; 130: 657-9.

6. de Peralta-Venturina M, Moch H, Amin M, Tamboli P, Hailemariam S, Mihatsch M, et al.: Sarcomatoid differentiation in renal cell carcinoma: a study of 101 cases. Am J Surg Pathol. 2001; 25: 275-84.

7. Sella A, Logothetis CJ, Ro JY, Swanson DA, Samuels ML: Sarcomatoid renal cell carcinoma. A treatable entity. Cancer. 1987; 60: 1313-8.

8. Bertoni F, Ferri C, Benati A, Bacchini P, Corrado F: Sarcomatoid carcinoma of the kidney. J Urol. 1987; 137: 25-8.

9. Ro JY, Ayala AG, Sella A, Samuels ML, Swanson DA: Sarcomatoid renal cell carcinoma: clinicopathological. A study of 42 cases. Cancer. 1987; 59: 516-26.

10. Cangiano T, Liao J, Naitoh J, Dorey F, Figlin R, Belldegrun A: Sarcomatoid renal cell carcinoma: biologic behavior, prognosis, and response to combined surgical re-section and immunotherapy. J Clin Oncol. 1999; 17: 523-8.

11. Mian BM, Bhadkamkar N, Slaton JW, Pisters PW, Daliani D, Swanson DA, et al.: Prognostic factors and survival of patients with sarcomatoid renal cell carcinoma. J Urol. 2002; 167: 65-70.

12. Cheville JC, Lohse CM, Zincke H, Weaver AL, Leibovich BC, Frank I, et al.: Sarcomatoid renal cell carcinoma: an examination of underlying histological 
subtype and an analysis of associations with patient outcome. Am J Surg Pathol. 2004; 28: 435-41.

13. Frank I, Blute ML, Cheville JC, Lohse CM, Weaver AL, Zincke H: An outcome prediction model for patients with clear cell renal cell carcinoma treated with radical nephrectomy based on tumor stage, size, grade and necrosis: the SSIGN score. J Urol. 2002; 168: 2395-400.

14. Selli C, Hinshaw WM, Woodard BH, Paulson DF: Stratification of risk factors in renal cell carcinoma. Cancer. 1983; 52: 899-903.

15. Pantuck AJ, Zisman A, Belldegrun AS: The changing natural history of renal cell carcinoma. J Urol. 2001; 166: 1611-23.
16. Figlin RA, Pierce WC, Kaboo R, Tso CL, Moldawer N, Gitlitz B, et al.: Treatment of metastatic renal cell carcinoma with nephrectomy, interleukin-2 and cytokine-primed or CD8(+) selected tumor infiltrating lymphocytes from primary tumor. J Urol. 1997; 158: 740-5.

17. Figlin RA: Renal cell carcinoma: management of advanced disease. J Urol. 1999; 161: 381-6.

18. Jocham D, Richter A, Hoffmann L, Iwig K, Fahlenkamp D, Zakrzewski G, et al.: Adjuvant autologous renal tumour cell vaccine and risk of tumour progression in patients with renal-cell carcinoma after radical nephrectomy: phase III, randomised controlled trial. Lancet. 2004; 363: 594-9.

Received: October 13, 2004

Accepted after revision: January 01, 2005

\author{
Correspondence address: \\ Dr. Marcos F. Dall'Oglio \\ Rua Barata Ribeiro, no. 398, 5o. andar \\ 01308 - 000, São Paulo, SP, Brazil \\ Fax: + $55113159-3618$ \\ E-mail: marcosdallogliouro@terra.com.br
}

